\title{
Miscelánea
}

\section{La construcción política de la desertificación: el desierto que repta}

\section{The political construction of desertification: the creeping desert}

\author{
Pedro TOMÉ MARTÍN \\ Instituto de Lengua, literatura y Antropología \\ ILLA Centro de Ciencias Humanas y Sociales \\ CCHS. Consejo Superior de Investigaciones Científicas \\ pedro.tome@cchs.csic.es
}

Recibido: 22 de octubre de 2012

Aceptado: 10 de junio de 2013

\begin{abstract}
Resumen
A partir de una serie de estudios etnohistóricos sobre la Guerra de los Chichimecas y del establecimiento de analogías con otros procesos que han tenido desiertos como escenarios, el artículo plantea que la noción de desierto es más una categoría de acción política que un concepto geográfico. Tras mostrar cómo acontece el proceso de invención de los desiertos, el artículo analiza el modo en que algunos de los componentes que caracterizaron a dicha invención están siendo trasladados analógicamente a los discursos dominantes acerca de problemas ambientales contemporáneos como la desertificación.
\end{abstract}

Palabras clave: Antropología del desierto, ecología cultural política, desertificación, desierto verde, parque natural.

\begin{abstract}
Drawing from a series of studies on ethnohistorical Chichimeca's War and through the establishment of analogies with other processes that have deserts as scenarios, this article argues that the notion of wilderness is more a category of political action than a geographical concept. After showing how the process of the social invention of 'deserts' takes place, the paper analyzes the way in which some of the components that have characterized this invention are being analogically transferred to dominant discourses about contemporary environmental problems such as desertification.
\end{abstract}

Keyword: Anthropology of the desert, Political Cultural Ecology, Desertification, Green Desert, Natural Park.

Referencia normalizada: Tomé, P. (2013) La construcción política de la desertificación: el desierto que repta, en Revista de Antropología Social, 22: 233-261. 
SUMARIO: 1. Introducción 2. Presentación del desierto 3. La invención del desierto 4. Dos breves analogías sobre "la conquista del desierto" 5. La desertización 6. La producción de desiertos 7. Las tierras improductivas 8 . El avance de una desertificación verde y sin arenas 9. Referencias biliográficas.

\section{Introducción}

El entusiasmo con que los decimonónicos viajeros románticos que recorrían todo el orbe conocido, y aún el mundo por conocer, descubrían en el paisaje la concreción de una fuerza telúrica de carácter casi divino, la naturaleza, marginó la ilustrada convicción de que aquel es siempre resultado de la acción de los seres humanos. Si el racionalista de fines del siglo XVIII mantenía que la inadecuada gestión política tornaba los espacios interurbanos en decadentes e improductivos yermos, el viajero romántico hallaba en la pintoresca magnificencia de la aridez del paisaje un objeto de seducción en que reflejar sus estados de ánimo. Así, donde el primero hubiera querido poner remedio a la desolación, el segundo anhelaba la quietud nacida de la ausencia de humana mano que pudiera modificar lo sublime. O dicho en términos más al uso en el siglo que hoy corre, el ilustrado hubiera clamado por una intervención política mientras el romántico proclamaría enfáticamente que cualquier intrusión humana minaría la supuesta capacidad de autorregulación de la naturaleza y, por ende, contaminaría su incólume esencia.

Entre ambos extremos cabe un mundo y la naturaleza toda. Conviene, no obstante, tenerlos presentes, por mucho que hoy en la práctica política, paradójicamente, haya ocasiones en que converjan (Castree, 2008). No en vano, cada día son más evidentes los efectos perversos que se derivan de un saber asentado en una nueva summa te(cn)ológica que se pretende hegemónicamente omnisciente. Efectos que, por lo demás, pueden trasladarse del mismo modo tanto a la inacción neoconservacionista de aquellos que, olvidando que nos hallamos en un "mundo postnatural" (McKibben, 1990: 55) en el que la "Naturaleza" ha sido abolida (Blühdorn, 2007), aspiran a una naturaleza inviolable, como a la actuación inicua de quienes considerándola como mero factor de producción, la convierten en laboratorio en que probar mudanzas genéticas o en patio colmado con la basura que originamos. Sin embargo, al menos dos evidencias muestran la peligrosa candidez de optar por un genérico punto medio entre los extremos aludidos. Por una parte, resulta relativamente sencillo verificar de modo reiterado la pertinencia de la denominada "segunda contradicción del capitalismo" que, en síntesis, plantea la existencia de una "apropiación y uso autodestructivo por el capitalismo de la fuerza de trabajo, del espacio y la infraestructura urbana, y de la naturaleza o el medio ambiente externo" (O'Connor, 1992: 112). Por otra, la pluralidad de factores que inciden sobre las múltiples condiciones ambientales particulares es tal, que cualquier generalización sobre los modos en que deben operar las relaciones entre los seres humanos y su entorno más inmediato, corre el riesgo de convertirse en mera futilidad cuando se intenta concretar en un ámbito local. Más aún cuando la "acumulación de capital" 
busca simultáneamente "proteger y degradar el mundo biofísico" (Castree, 2008: 150) y cuando la aparente confrontación entre desarrollo y conservación, puede ocultar una pugna entre dos formas diferentes de mercantilizar la naturaleza que genera profundas desigualdades y desequilibrios ecosociales (Santamarina, 2006; 2009). Es más, en numerosas ocasiones "los discursos de 'modernización ecológica', 'sostenibilidad', 'consumismo verde' o mercantilización y comercialización de la 'naturaleza' como un espectáculo cultural" revelan "el vigor increíble con que los intereses dominantes han tratado de contener, formar, desmitificar y embarrar el contemporáneo debate sobre la naturaleza y el medio ambiente" (Harvey, 1993: 39).

Éste, no obstante, se tornó inaplazable en el ámbito de la antropología tras la convergencia, hace algo más de tres décadas, de los estudios de género y la etnoecología derivada de la antropología cognitiva. La consideración de la "naturaleza" como una construcción social y no como un ente presocial dado, que venía anticipándose en diversas etnografías, se tornó ineludible tras la publicación por parte de Marilyn Strathern de su estudio sobre los hagen de Papúa Nueva Guinea. En el mismo, Strathern apuntó la imposibilidad de utilizar la "occidental" dicotomía naturaleza-cultura para comprender esas relaciones entre los hagen debido a que en su sistema de pensamiento "la naturaleza no se manipula" (1980: 175). La constatación de la diversidad de procesos cognitivos, en el sentido de Bloch (1989), obligó a considerar que nociones como "naturaleza" se encuentran insertas en "una tradición intelectual específica dentro de nuestra propia cultura" (Strathern, 1980: 176). Aseveraciones de este tenor llevaron a autores como Ingold (1986), a pesar de su crítica al constructivismo social extremo, a plantear la posibilidad de que aprehender la naturaleza en cuanto tal, sea imposible tarea. En todo caso, esta posición no condujo inexorablemente a un relativismo autista sino a una revisión crítica de la noción misma de "naturaleza." En última instancia, el concepto "occidental" de la misma, más allá de los significados que podemos atribuirle (Ellen, 2001), resulta "polifacético y ambiguo" (Milton, 1997).

La discusión acerca del significado último de nociones como "naturaleza" no es una cuestión para diletantes ni una controversia meramente semántica: "la transformación ontológica de la naturaleza", que ha supuesto la "creación" de nuevas formas y la irrupción de diferentes "regímenes de naturaleza" (Escobar, 1999), revela un ámbito de expresión de conflictos políticos que hallan una vía adecuada para manifestarse en la "ambigüedad de la noción, abierta a una gran diversidad de interpretaciones" (Harvey, 1993: 2). Máxime cuando los modelos locales evidencian un arraigo especial a un territorio concebido como una "entidad multidimensional que resulta de los muchos tipos de prácticas y relaciones; y también establecen vínculos entre los sistemas simbólico/culturales y las relaciones productivas que pueden ser altamente complejas" (Escobar, 2000: 72). Por lo mismo, resulta forzoso incorporar la convicción de que la descripción de los espacios, en que supuestamente halla expresión esa "naturaleza" externa, no se realiza con unas categorías "objetivas" de pensamiento. Tal idea no es más que un vestigio positivista de la metafísica cartesiana acríticamente asumido por parte de los saberes actuales (Lefebvre, 1974). Así, en la medida en que el recuento de los estudios etnográficos descubre una 
gran variedad de formas locales de concebir y relacionarse con lo natural, esto ya no puede definirse desde su anclaje en la dicotomía naturaleza-sociedad (Escobar, 1999) o naturaleza-cultura (Descola, 2001). A la vez, como señala el mismo Lefebvre, esos modos diferenciados de relacionarse con lo natural "producen" formas igualmente diferenciadas de espacios y tiempos que, por una parte, se ven implicadas en los procesos "naturales" y "sociales" y, por otra, las producen. Justamente por ello, si se pretende elucidar qué ideas o prácticas subyacen a determinadas nociones de "naturaleza", es necesario utilizar enfoques de carácter histórico.

Estos permitirán descubrir, de un lado, cómo los paisajes son fruto de construcciones sociales en las que las características ecosistémicas pueden ser resultado de las acciones humanas y, de otro, la forma en que esas acciones, sus efectos y la relación con el entorno se han conceptualizado. Además, si la conformación de cualquier ecosistema, como dijera Harvey (1993: 27), está impregnada de "relaciones sociales", también estarán "inscritos" en él los "patrones de autoridad", tal y como sugiere Scoones (1999: 494) al analizar los estudios sobre las perspectivas ecológicas "institucionales". En suma, resulta crucial observar cómo ha podido evolucionar la descripción de lo natural por cuanto "la terminología ayuda a naturalizar las relaciones sociales de poder y sus prácticas distintivas" (Harvey, 1993: 14). En parte porque, las más de las veces, "el marco de interpretación" de la "naturaleza" se encuentra en las metáforas que utilizamos para describirla (Harvey, 1993: 15).

Si bien las páginas precisas para abordar una cuestión como la planteada excederían con mucho las que este artículo puede contener, las que siguen plantean un esbozo de cómo, con excesiva frecuencia, el discurso y los conceptos utilizados en la concepción del desierto son fruto de una construcción política inherente a un modelo de conquista y colonización desarrollado por parte de Estados nacionales. En ese sentido, las líneas siguientes se centran en cómo se han desarrollado algunos discursos de legitimación de la conquista a través de la creación de un determinado paisaje. Tomando como eje de la reflexión el modo en que fue configurado el "desierto de los chichimecas", estas páginas bosquejan cómo discursos semejantes pueden encontrarse analógicamente en otros procesos de conquista desarrollados en tiempos y lugares diferentes o de acuerdo con lógicas aparentemente muy distantes.

\section{Presentación del desierto}

La puerta, solamente sugerida en la oscuridad, comienza a abrirse lentamente para que la visión de la inmensidad sobrecoja al espectador. Atrás, dentro, queda en sombras el espacio doméstico. Delante, fuera, el desierto se abre como una extensión sin confines. Así arranca The Searchers, la película dirigida en 1956 por John Ford que se titularía en España Centauros del Desierto y en algunos países iberoamericanos Más corazón que odio. En este filme el desierto no es meramente el escenario que recorre Ethan, John Wayne, en busca de su sobrina Debbie, Natalie Wood, sino un personaje más de la película: el lugar donde los peligros para la vida "civilizada" se acrecientan en la hora del crepúsculo, el espacio en que sólo es posible el salvajismo y la antítesis, en definitiva, de la casa de la que la niña fue raptada. La película establece una contraposición entre esa casa, la granja como naturaleza 
"domesticada", y el territorio salvaje e indómito donde reinan los comportamientos inhumanos. De tal forma domina el paisaje a los que en él se adentran, que el "explorador" es presentado como un genuino desalmado, aunque persiga fines loables. Tal es la fuerza negativa del desierto que la secuestrada, tras vivir en él durante gran parte de su vida, para suplicio del fanático racista, se ha convertido en una "india" mimetizándose con el paisaje. En suma, frente a la compasiva racionalidad doméstica, el desierto es, en la película, el inquietante espacio de la irracional ferocidad, el territorio vano al que quedan condenados aquellos que no asumen las reglas de la colectividad "civilizada".

Aunque puede señalarse que esta película de John Ford nos presenta la visión que éste (o su guionista Frank S. Nugent que, a su vez, se basó en la novela homónima de Alan Le May) tenía del desierto (y de los seres humanos), cabe plantearse si esta mirada podía exceder los límites que, en relación con este tipo de ecosistemas, delimitan lo pensable, en el sentido de Foucault. O dicho de otro modo, el complejo categorial que se anuda en torno a la noción de desierto existente en esta película no difiere del que la "literatura de conquista" ha elaborado para aplicar a momentos, lugares o situaciones parcialmente análogas, como el único verdaderamente posible. Este "discurso occidental" puede rastrearse fácilmente desde composiciones medievales como el Poema de Mío Cid ("estéril y pobre es aquella tierra tan mala"), hasta contemporáneas producciones culturales (películas como Star Wars, Mad Max, Total Recall -Desafio Total, en España o El vengador del futuro en Iberoamérica-, Acción Mutante, narraciones literarias tan dispares como las Crónicas Marcianas de Ray Bradbury, The Road de Cormac McCarthy o El arte de la resurrección de Hernán Rivera Letelier, etc.) que pretenden describir mundos distópicos o contraponerlos ya a utopías deseables ya a realidades presentes o intuidas. Diríase que este discurso se caracteriza por presentar a sus protagonistas - sean literarios, cinematográficos o deportistas que escalan montañas - insertos en paisajes hostiles. Como si la hostilidad fuera un elemento incontrovertible de la propia naturaleza y no una metáfora con que la interpretamos. En todo caso, si la presencia de tan adversos contextos produce una gran incertidumbre e inseguridad, la soledad del riesgo contribuye de manera decisiva a exteriorizar un modo euro-norteamericano de presentar los desiertos como la inhóspita e insegura frontera. Es más, salvo para quiénes los habitan, tal pareciera que los desiertos se conciben desde la categoría de "lugar atributo" (Aldhuy y Puyo, 2007), como espacios a los que se "atribuyen" o de los que se predican ciertas características con independencia de que éstas se acomoden a lo que una contrastación empírica mostraría. Da igual, en este sentido, de qué desierto se hable, pues en la imaginación de quien no los conoce no hay distinción entre Atacama, Gobi, Kalahari o el Sahara: todos son desiertos y, por tanto, lo que a uno se atribuye, de todos se predica. Esta uniformidad procede de una percepción ideológica oculta bajo un aparente velo de objetivismo geográfico que, si bien con numerosos matices particulares, se ha forjado históricamente de acuerdo a los elementos constitutivos de lo que Renato Rosaldo (1978) llamaba la "retórica del control" y que, en este ámbito, se concreta en la desaparición de las diferencias ecosistémicas y sociales en un espacio dado. 
Si bien no hay duda acerca de la heterogeneidad ecosistémica de los desiertos, la imagen estereotipada que de ellos tenemos es la del territorio en que no hay nada ni nadie. Y ello, por mucho que, según el Programa de Naciones Unidas para el Medio Ambiente, las 72 ecorregiones susceptibles de ser consideradas desiertos en el mundo albergaran en 2006 a más del 8\% de la población mundial: entre 143 millones de personas, si se toma el término desierto en sentido estricto, y más de 502 millones si se toma de forma amplia (Ezcurra, 2006). Ahora bien, este imaginario dominante posee implicaciones sociales y políticas pues, en cuanto que antítesis del lugar civilizado, presenta el desierto como el territorio salvaje, indómito o virginal, que puede ser conquistado por la audacia de "nuestra" imparable civilización que sobrepasa cualquier frontera - y no sólo geográfica. Es decir, la frecuente equiparación entre desierto y frontera (recuérdense, por ejemplo, las tesis de Sánchez Albornoz sobre el "desierto medieval del Duero" (1966) permite el fácil salto desde la concepción de "tierra vacía" a la de "tierra de nadie", aunque en ella habiten infames enemigos. Pero "tierra de nadie" es "tierra apropiable" por pioneros, misioneros, conquistadores, comerciantes, etc. Apropiable, en última instancia, por cualquiera de los "nuestros". Es decir, el desierto se presenta como el territorio ajeno, el no-lugar de los no-nosotros, que, no obstante, precisamos para nuestra expansión, para seguir siendo nosotros. Es más, en cuanto que concreción espacial de lo absolutamente "otro", si alguien viviera allí sería, como la propia tierra, "salvaje" y, en la medida en que habitante del territorio aborrecible/apetecible de la hostilidad, aniquilable cultural o materialmente.

\section{La invención del desierto}

El avance hacia el noroccidente de los ejércitos hispanos que habían tomado Tenochtitlan se encontró con una enconada resistencia de los grupos genéricamente denominados chichimecas que derivaría en una abierta confrontación bélica. Hernán Cortés (1986: 426), al dar las primeras noticias en 1526 sobre los citados chichimecas, señala que "son gentes muy bárbaras y no de tanta razón como estas otras provincias" de las que supone que "entre estas gentes hay cierta parte muy poblada de muchos y muy grandes pueblos y que la gente de ellos viven a la manera de los de acá". También da noticias de ellos Fray Bernardino de Sahagún quien, tras mostrar "cuántas maneras de chichimecas ha habido en esta tierra", (1995 II: 655), concluye que "la verdad no se llaman tierra de chichimecas por donde ellos anduvieron, sino Teotlalpan Tlacochcalco Mictlampa, que quiere decir 'campos llanos y espaciosos que están hacia el norte'. Llamáronse tierras de chichimecas porque allí suelen ahora habitar los chichimecas, que son unas gentes bárbaras que se sustentan de la caza que toman, y no pueblan." (1995 II: 676) Es decir, tanto Cortés como Sahagún hablan de gentes que les parecen menos "civilizados" que los aztecas ("muy bárbaras y no de tanta razón") que habitan áreas densamente pobladas ("muchos y muy grandes pueblos") y son nómadas cazadores ("no pueblan").

Ya he indicado en diversos lugares (Tomé, 2008; 2010; 2012b) que tan genéricas descripciones mudarán considerablemente tras desencadenarse la "batalla del Mixtón" (1541-1542) que daría paso a la "Guerra de los chichimecas" prolongada hasta 
1597. Conoceremos entonces que los llamados chichimecas son un heterogéneo grupo de "parcialidades" (pames, guachichiles, guamaraes, zacatecas, etc.) que no comparten la misma lengua ni numerosas costumbres y que, aunque efectivamente no pueblan - "no les dan pena el dejar su casa, pueblo, ni simentera, pues no lo tienen, antes les es más cómodo vivir solos de por sí, como animales o aves de rapiña" (Santa María, 2003: 206) —, solamente se han unido para la defensa: "no se juntan unos con otros para mejor mantenerse y hallar su comida, y ansí éstos nunca se juntarían si la necesidad de la guerra no les compeliese a vivir juntos." (ibídem) El mismo fraile agustino (Santa María, 2003: 219) plantea la existencia de otras alteraciones que la guerra ha traído en el modo de vida de los chichimecas sugiriendo que la situación bélica les ha llevado a asentarse y ocupar territorios que antes les eran ajenos. Esta radical transformación permitiría cuestionar, igualmente, si, al menos en algunos grupos, el propio nomadismo era también fruto de la misma situación (Tomé, 2012a). En apoyo de esta incertidumbre vendrá la Relación breve y verdadera de algunas cosas de las muchas que sucedieron al padre fray Alonso Ponce escrita justo cuando la contienda declinaba. En la misma se señala que estando en San Pedro Tanauehpa se le acercaron "siete u ocho indios chichimecas de la sierra, con cabellos largos y zarcillos en las orejas (...) que aunque los años pasados se habían subido a la sierra huyendo de miedo de los soldados que los maltratan, ya se habían bajado a lo llano" (Ponce, 1873: 70). Es decir, se podría apuntar que durante la conquista se atribuyó la condición de "nómadas salvajes" a todos aquellos grupos que formaban parte de la resistencia a la extensión del imperio, con independencia de cuál fuera su modus vivendi con antelación a la llegada de las tropas (Tomé 2012a; 2012b). Ejemplo de ello sería la inclusión en algunas definiciones de los tepehuanes como chichimecas aún siendo sedentarios. Como diría Alonso de Ponce en su relación de 1587, "todos estos indios de guerra son llamados comúnmente chichimecas de los españoles, y aun de los indios mexicanos y tarascos" (Ponce, 1873: 134). Con ello, el término "chichimeca" que inicialmente pretendía clasificar someramente a los grupos indígenas que habitaban al norte del país, con el paso del tiempo se convertirá casi en un término legal: chichimeca será quien no se ajustara a los estándares productivos exigidos por el conquistador y se resistiera a la expansión territorial de la colonia (Gradie, 1944).

Por otra parte, antes de que eso ocurriera, la discusión sobre la legitimidad de la conquista del territorio chichimeca propició numerosos "pareceres" solicitados por las autoridades civiles y eclesiásticas españolas (Carrillo, 2000). En buena medida, éstas contribuirán a conformar un marco categorial en el que se engrendraría una representación más moral que geográfica tanto del espacio a conquistar - tierra estéril — como de sus moradores - enemigos - Frente al bíblico y exuberante edén del que el legitimador de la conquista hacía nacer la civilización, el territorio chichimeca adolecía de todo. Explicar a un lector que en la distancia ultramarina tenía que comprender la justificación de la conquista exigió, además, una representación del salvaje desde una categoría que explicara su supervivencia en tan estériles tierras: subsistían gracias a la caza y recolección que, como nómadas, practicaban (Tomé, 2003). Así, en la práctica, los términos nómada y chichimeca devinieron sinónimos 
pues considerarlos agricultores equivaldría a la contraditio in terminis de tenerlos por "civilizados": jamás podrá ser civilizado quien, según los cronistas, habita en una tierra desolada, inhóspita, intransitable y, en definitiva, siniestra (Giménez y Héau, 2008: 80).

El fin de la guerra no significó la identificación de chichimeca e "indio de guerra". Más bien, descripciones como las realizadas por Alonso de Ponce, integrarán los elementos positivos y simultáneamente negativos que los chichimecas representan para la corona:

$[\mathrm{N}] \mathrm{o}$ tienen necesidad de llevar consigo vituallas ni aparatos de guerra, como los españoles, sino solamente arco y flechas, porque donde quiera que llegan hallan que comer raíces, yerbas, tunas y lechuguillas, que son maguey silvestre, y mezquite, que es la fruta de un árbol de que hacen pan, con lo cual se sustentan y viven anos, recios y valientes. La tierra que poseen parece mucho a la de nuestra España: dánse en ella muchas y muy buenas uvas, higos y otras frutas de Castilla, y se daría trigo y cebada, y todo lo demás que se da en las tierras frías de España. Dase también mucha tuna y hay maravillosos pastos y infinidad de ganado mayor. (Ponce, 1873:138)

Esta simultaneidad de patrones particulares de "indios enemigos" y "pacificables", permitirán una transposición de las características de los primeros a los segundos y, por extensión a cualquiera que se negara a integrarse en el sistema colonial. Todavía, mediado el siglo XVIII, el Marqués de Altamira al referirse a los chichimecas jonases de la Sierra Gorda indica que:

[C]omo ya de ciento y treinta años lo escribió el Padre Torquemada en sus libros de la 'Monarquía Indiana', expresando que dichos indios Chichimecas eran los más bárbaros de toda esta Nueva España, insociables e irreductibles, lo cual y bien largamente se ha experimentado, en estos apóstatas bárbaros Chichimecas, Jonases, reducidos a principios de este siglo. (Marqués de Altamira, 1944: 27)

Así pues, en 1748, es decir, solo sesenta años antes de la Independencia, con la colonia totalmente avanzada y ciento cincuenta años después de que la conquista hubiera concluido, el citado Marqués, tras reiterar con varios ejemplos que los chichimecas jonases son "absolutamente negados protervos y obstinados", concluye aseverando que "no había otro modo de librarse de las atrocidades de dichos indios, que extinguiéndolos enteramente" (1944: 28). Es decir, las bases que durante la conquista se asentaron, fueron potenciadas durante la colonia para que hasta nuestros días el término "chichimeca" mantuviese su sentido despectivo (Tomé, 2010).

Este marco fue posible porque la tríada "nómada-territorio desértico-salvaje", en la que territorios y personas son indistinguibles, sirvió sobradamente para justificar la conquista de un espacio que, previamente, fue vaciado simbólicamente. Es decir, tomados los chichimecas como nómadas, con mínimas resistencias morales aducidas por algunos misioneros, se les pudo desposeer de sus tierras, pues como gentes "sin asiento" ni "sementera", que decía Fray Guillermo de Santa María, ninguna tenían propia. Una vez que se niega el asentamiento, se caracteriza el espacio como 
"apropiable" por quien en él se instale. De este modo, la penetración en lo que se llamó el desierto chichimeca, se asimiló al avance de la civilización, concretada en el otorgamiento de propiedad de la tierra. Además, la propiedad de la tierra incluía, desde la perspectiva conquistadora, la legitimadora idea del "progreso moral". Con ello, se atemperó la condición desértica de un espacio que desde un punto de vista geomorfológico, biológico y climático no se había visto alterado. Es decir, la extensión de presidios y la traza de nuevos caminos (siguiendo las rutas de los antiguos), suponía una apropiación tanto material como simbólica del territorio que excluía la condición desértica del mismo, por mucho que el número de colonos pudiera ser menor que el de los habitantes que había antes de la conquista.

En este sentido, la reapropiación supuso una recategorización del territorio pues parecería absurda una decisión política que había concitado tal gasto energético, económico y, en definitiva, humano, para colonizar páramos yermos y baldíos. Esta recategorización territorial pone de manifiesto cómo gran parte de los discursos sobre el territorio chichimeca eran metonímicos, puesto que predicaban del todo lo que sólo era atribuible a partes. De hecho, donde algunos cronistas de conquista vieron tierra yerma, veían los rancheros prestos a ocuparlas "tierra fértil de riego" y de "muchas agua", (Powell, 1971: 251) por lo que, ya antes de que concluyera el siglo XVI, solicitaron al Virrey que exterminase a unos chichimecas que ocupaban un territorio apetecible: "los dichos yndios tienen tomada y ocupada mucha tierra y la mexor y más rrica de toda la nueua españa tierras muy fértiles e muchas minas rricas descubiertas y por descubrir" (Powell, 1971: 257).

Esta petición pone de manifiesto que las necesidades de la colonia no son las mismas que las de la conquista y que, por tanto, los discursos que legitiman una y otra han de ser diferentes incluso en la descripción del territorio observado. O lo que es lo mismo, la demanda ranchera hace ostensible que la descripción de los paisajes desérticos no tenía tanto que ver con una visión pretendidamente objetiva del paisaje sino con la aludida retórica del control. Por eso, ocupado el territorio y finalizada la contienda abierta, era preciso enculturar a los chichimecas vivos, eliminar totalmente su condición salvaje mediante su incorporación como mano de obra al trabajo agrícola. Si la consideración del chichimeca como nómada salvaje tuvo más que ver con las necesidades económicas del imperio que con una base étnica, ocurrió lo propio con el territorio en que habitaba: fue desierto mientras se precisaba legitimar su conquista. En este contexto, el modelo de integración propuesto llevaba en sí mismo el germen del exterminio cultural e incluía la posible aniquilación material de quien no optara por ella. Si el nómada deja de serlo y siembra, si pasa a ser "sujeto a pueblo" y "sujeto de pueblo", se consideraría integrado con independencia de cuál fuera su lugar de residencia pues la producción en términos de "las necesidades del mercado" elimina la condición de "desierto" del lugar en que habita. En suma, la conquista del territorio de los antiguos chichimecas pone de manifiesto cómo la descripción del territorio como desierto incluía una representación ideologizada del mismo que, en muy buena medida, sigue perdurando más allá de los tiempos coloniales (Tomé, 2010). 


\section{Dos breves analogías sobre la "conquista del desierto"}

La identificación de agricultura con civilización y de nomadismo con salvajismo y la consecuente representación de un territorio como desierto o fértil en función de necesidades exógenas de quienes lo habitan, puede hallarse analógicamente en otros momentos y espacios, a pesar de las lógicas dificultades que comporta establecer parangones sobre procesos acontecidos en diferentes tiempos y lugares, y alcanza adecuada expresión en las teorías decimonónicas de la evolución sociocultural. Estas teorías, entre otros principios, creían poder constatar el "progreso moral" de la humanidad no sólo por avances científicos y tecnológicos sino por su capacidad para integrar en el sistema productivo los espacios que permanecen fuera de él.

Este motivo ha permitido identificar como desierto cualquier espacio incógnito o improductivo al margen de que posea una exuberante vegetación o agua en abundancia. Baste recordar las palabras con que en 1876 Juan Ballinas inicia su segunda exploración del que llama Desierto de los Lacandones: "había penetrado veinticinco leguas en el desierto de lacandones y sólo había visto sus selvas, su abundante caza y sus abundantes aguas" (Ballinas, 1951: 30). Por la misma razón, las Landas francesas fueron tenidas hasta hace dos siglos como un "mal país marcado por la imagen del desierto" (Aldhuy y Puyo, 2007: 238) ya que el número de árboles era tan abundante que no había forma de sembrarlo. Además, como había ocurrido en el caso de los chichimecas, la identificación entre tierras y gentes, llevó a describir en numerosas ocasiones a los habitantes de las Landas como nómadas por mucho que mantuvieran una sedentaria economía silvo-pastoril. Es decir, la visión colonizadora ha definido como desierto cualquier lugar, fuera ciénaga o secarral, que por su impenetrabilidad u hostilidad no fuera apropiado para la producción agrícola ya que "el paradigma cultural europeo-occidental asignó la categoría de desierto no a los territorios deshabitados ni estériles sino a los no apropiados ni trabajados según las pautas capitalistas" (Navarro, 2002: 140).

La validez de este aserto se verifica atendiendo al modo en que discurrió la conquista del "desierto argentino" en el último tercio del siglo XIX, cuyos discursos de legitimación, a los que por mor del espacio me referiré someramente, recuerdan a los que fueron utilizados en el avance de la frontera a través de los territorios chichimecas. Considerado desierto, es decir territorio vacío, debido a que la impenetrabilidad de sus bosques hacía de él un terreno desconocido, el norte argentino fue asociado a la ausencia de civilización a pesar de que en él habitasen numerosos grupos originarios. Ahora bien, en el proceso de construcción nacional, "la estatalidad se impone sobre la nada" y hace del desierto el "escenario óptimo para la civilización" (Lois, 1999). Esto fue posible, junto a otros factores, por las aportaciones de un positivismo geográfico que favoreció una "apropiación intelectual" del espacio como paso previo a su apropiación material:

[P]or un lado, un área no cartografiada era, supuestamente, un área desconocida y podía ser llamada desierto pese a sus "inmensas riquezas naturales"; pero, por otro lado, en el contexto del imperialismo europeo y del auge del positivismo, los desiertos "debían" ser colonizados, apropiados y cartografiados. Es decir, pensar el 
desierto implicaba necesariamente la urgencia de vaciarlo y transformarlo mediante la apropiación nominal y simbólica, en un no-desierto. (Lois, 1999)

Esta idea jugó un papel fundamental en la legitimación de un determinado modelo de construcción nacional en la que el "progreso" debía ajustarse al "orden" predeterminado y en el que "al hablar de desierto se habla metafóricamente de barbarie, anulando en parte su significación "geográfica", porque se anula la significación topográfica, pero, paradójicamente, se la conserva para aprovecharla en beneficio de su aceptación y legitimación en términos de cientificidad" (Lois, 1999).

Al ser "conquistado" y conocido, operará una resignificación de la dicotomía "civilización-barbarie" en la que el territorio ocupado dejará de ser desierto por mucho que sus condiciones ecosistémicas no variaran un ápice. La potencia de esta metáfora geográfico-cultural debe vincularse explícitamente al discurso de construcción de un proyecto nacional que precisaba de la exclusión de cualquier alteridad posible. Así pues, "hablar de desierto, era hablar de espacio. En cambio, hablar de Chaco era hablar de indígenas" (Lois, 1999). Por lo mismo, "el desierto no era desierto, sino que debía ser desierto" y tal proceso de construcción simbólica del espacio debía acompañarse con un proceso de desalojo-ocupación, o dicho de otro modo, de "liquidación de indios/convocatoria de inmigrantes" (ibídem). En este contexto, la necesidad de apropiación del espacio, y su consecuente conversión en no-desierto, precisó de una previa categorización del mismo en un desierto habitado por salvajes. Así pues, salvaje era quien no producía en términos agrícolas o ganaderos, quien persistía en una vida nómada $y$, en definitiva, cualquiera que, con independencia de su origen étnico, no mostrase una favorable predisposición a "integrarse" en el avance de un nuevo Estado. Es decir, el peligro para esa nueva estructura política venía no de unos grupos más o menos armados que ofrecían una cierta resistencia al corrimiento de las fronteras externas, sino de la exhibición de un posible orden alternativo. La identificación de los grupos indígenas habitantes del desierto argentino con el nomadismo sirvió, a su vez, para no considerarlos sujetos de derechos en un país que se estaba forjando. $\mathrm{Si}$, se decía, permanecen fieles a un modo de vida que el Estado situaba al margen de la sociedad, los derechos que a los miembros de ésta le eran aplicables, no tenían por qué extendérseles. Así pues, la eliminación de los "derechos aboriginales" fue crucial en lo relativo al derecho a la propiedad de la tierra, pues, utilizando los términos de Domingo F. Sarmiento (entre comillas), señala Navarro que:

[F]ue la asignación generalizada del rasgo del nomadismo, en el debate de 1867, lo que privó a los "indígenas" de sus derechos a la tierra y lo que los convirtió en enemigos, dado que "no tienen derechos a determinada porción del territorio porque, son tribus nómades" y "no viven ni saben vivir en un punto fijo", y "no viven ni saben vivir en un punto fijo", que "por el mismo extremo de su barbarie han de oponer resistencia" y por tanto "no merecen consideración alguna". (Navarro, 2001: 356) 
En suma, la incapacitación como "propietario", a la que subyacía la idea del extermino cultural, supuso la transformación de una frontera exterior en una interior con la conquista del desierto como excusa. Para el desarrollo de ésta, existía una fuerte legitimación sociopolítica con un proceso que aparentemente combatía al desierto pero no al indio: la "búsqueda de la seguridad territorial" se hacía conquistando y colonizando, es decir, llevando riqueza agropecuaria a terrenos antes estériles. Claro que la alteración radical de los ecosistemas implicaba de hecho privar a los indígenas de sus modos de subsistencia y condenarlos bien al sometimiento y aniquilación cultural, bien a la muerte. En última instancia, en relación con el desierto operó aquí una "una cierta conceptualización política (no geográfica) de él como escenario que posibilita el salvajismo" (Navarro, 2002: 165). Ahora bien, si el enemigo puede ser derrotado mediante la repoblación civilizadora o productiva es porque a dicha visión subyace la idea de que la tierra, fértil y rica, llena de riquezas, puede ser ocupada con la incorporación de migrantes que dinamicen la economía del nuevo Estado.

Este esquema no es, por lo demás, muy diferente del que, en la transición del siglo XIX al XX, defendiera Frederick Jackson Turner (1961) al presentar la historia de los Estados Unidos como el continuo avance de la civilización sobre la tierra vacía. En "The significance of the Frontier in American History", escrito en 1893, equiparó la historia de los EE.UU a una página de la historia de la evolución sociocultural en la que, línea a línea, puede "leerse el registro de la evolución social". Visto el país de oeste a este, el compendio se iniciaría "con el indio y el cazador", menos evolucionados socioculturalmente, para proseguir con "la desintegración del salvajismo por la entrada del comerciante". A partir de ese punto, y siguiendo el avance de la historia, esto es, la geografía estadounidense en dirección al naciente, nos encontraríamos con la "vida pastoril" ranchera, antes de hallar a las sociedades agrícolas. Entre éstas aparecerían, en primer lugar, las sociedades hortelanas y "escasamente pobladas" que cultivan maíz y trigo sin establecer rotaciones en la explotación del suelo y, posteriormente, las más evolucionadas granjas y establecimientos agrícolas dedicados al cultivo intensivo. Por último, la costa oriental nos ofrecería el paradigma del avance cultural y demográfico al exhibir "la organización de la producción con la ciudad y el sistema de fábrica" (Turner, 1961: 43).

Así pues, con una visión que retomaría en 1914 en "The West and American Ideals", Turner identifica el avance de la civilización con el de la frontera, con la invasión del desierto, es decir del territorio ajeno. Ahora bien, en el primero de los artículos mencionados, Turner se ve en la necesidad de reconocer que el desierto es un medio ambiente que, como en el filme de John Ford, puede imponerse sobre el ansia civilizadora. Por eso, inicialmente, "el desierto domina al colono" (Turner, 1961: 39) le obliga a despojarse de sus civilizadas vestiduras y a calzarse los mocasines de los indígenas. Tal es la fuerza del desierto que a quien en él quiera sobrevivir le impone la necesidad de habitar en cabañas similares a las de los cherokee y construir empalizadas como las de los iroqueses. En poco tiempo, aquel que se consideraba civilizado 
[...]grita el grito de guerra y toma el cuero cabelludo a la manera india ortodoxa. En resumen, en la frontera el medio ambiente es al principio demasiado fuerte para el hombre. Debe aceptar las condiciones que proporciona, o perecer, y así él mismo se ajusta a los claros indios y sigue los senderos indios." (Turner, 1961: 39)

La mímesis con el territorio desértico estaría, según Turner, en la génesis de lo americano. Si, en un primer momento, la costa atlántica fue "la frontera de Europa en un sentido muy real", la conexión con el Viejo Continente fue perdiéndose a medida que se conquistaba el oeste. Así, asevera, "la frontera es la línea de la americanización más rápida y eficaz" (Turner, 1961: 39) y, por tanto, su avance instituye lo americano. Ahora bien, este proceso de separación de lo europeo, de independencia, es posible porque, como ocurriera entre los conquistadores que se adentraron en territorio chichimeca o en el del desierto argentino, a medida que el pionero avanza, la tierra promisoria y, por tanto apropiable, es vaciada de sus habitantes originarios y ocupada por un "un nuevo producto que es americano" (ibídem). En ese sentido, según Turner, la "civilización americana" no nace de un lugar o hecho fundacional, sino de una actividad desarrollada por miles de personas: la ocupación progresiva de territorios que fueron considerados desiertos vacíos, al margen de que lo fueran, y su consecuente conversión en tierra habitable.

El avance de los pioneros sobre las Grandes Llanuras, la conquista del desierto argentino y la del territorio chichimeca son hechos incomparables pues suceden en contextos históricos y geográficos diferentes. Sin embargo, los discursos de legitimación empleados en los tres casos muestran procesos análogos y recurrentes de producción o invención de desiertos: la descripción de un espacio como territorio "desierto" supone la invisibilización de sus habitantes que se hacen inexistentes para quien quiere ocupar el espacio; de modo inmediato, esta representación del territorio genera una suerte de horror vacui que demanda el urgente llenado de "civilización". Es decir, la sinonimia entre desierto y tierra que ocupar, controlar o conquistar, muestra una retórica construcción de un territorio "vacío" a través de una desocupación simbólica; ésta es seguida de una apropiación nominal, la caracterización del espacio como "tierra de nadie", como paso previo a una ocupación material y efectiva con un carácter supuestamente civilizatorio.

\section{La desertización}

Si la definición de un lugar como desierto es una ilusión necesaria para legitimar una ocupación, habrá que colegir que el término desierto es más una categoría de acción política que una noción geográfica. Por lo mismo, los conceptos que se hallen dentro de su mismo campo, por ejemplo "desertización", deberán ser contemplados desde una perspectiva semejante. O sea, si los límites de los desiertos vienen determinados por procesos sociales y culturales, nociones como "desertización", entendida como producción o extensión de desiertos, vendrán igualmente condicionadas por dichos procesos.

Resueltas las necesidades más urgentes que la Segunda Guerra Mundial había provocado, mientras nuevas cotas de bienestar se iban prefigurando en la sociedad 
europea y estadounidense, los medios de comunicación comenzaron a fijar su vista en parajes africanos que, sin resonancias de la contienda reciente, evocaban exóticos destinos. Nuevos paisajes comenzaron así a adentrarse en los salones domésticos gracias a la televisión. Y, sin embargo, para el europeo medio, estos nombres no hacían referencia a desconocidos territorios pues aludían a espacios que eran o habían sido colonias cercanas. No obstante, ya no era el ficticio y reconfortante esplendor de la sociedad colonial lo que aparecía en las imágenes sino asolados cobijos en medio de los cuales niños desnutridos se postraban en espera de una ayuda ausente. Y, así, mientras en las viviendas de las clases medias y acomodadas se cenaba confortablemente, las grandes hambrunas tornaron en cotidianos nombres como Biafra o Eritrea. Con ello, las tierras del Subsahel y del Cuerno de África dejaron de ser el espejo de nirvanas lejanos para convertirse en la concreción de terribles pesadillas. A medida que el tiempo y la insensibilización avanzaban, la cotidiana y subrepticia asociación de las imágenes del desamparo y de los desérticos terrenos en que éste sobrevenía, generó una confusión entre escena y escenario. Y así, lo que fue inicialmente escenario, la extrema aridez, fue cubriendo de tal modo la escena, que la agonía humana se transformó en personaje secundario reducido a indiferente cifra. Tomados los muertos como mero dato estadístico a manejar por los corresponsales de prensa, el foco de atención fue trasladándose gradualmente desde las personas hasta el entorno en que éstas deambulaban, desde la acción humana a un indefinido y desbocado avance del desierto. El descubrimiento de esta incontrolada fuerza de la naturaleza permitió hallar una causa impersonal que, desarrollada al margen de las estructuras político-económicas que propiciaban la pobreza, explicaba la muerte de millones de hombres y mujeres. Así, problemas ambientales que, se decía, eran ajenos a la acción humana - quién puede decidir que llueva y se extienda la sequía- y no estructuras políticas vinculadas a heterogéneos e inconclusos procesos de colonización y descolonización, pasarían en el discurso dominante a considerarse los desencadenantes de tanta muerte. O lo que es lo mismo, las mortandades pudieron presentarse como infortunados efectos de un desastre natural. ¡Cómo si la degradación ambiental de esas tierras fuera efecto de una fatalidad contra la que no se podía hacer nada y no fruto del saqueo!

En este marco, el concepto de "desertificación", de uso común entre científicos sociales desde finales de la década de los 40 (Aubreville, 1949), se difundió hasta convertirse en centro de atención de numerosas discusiones. Es más, aunque ya la UNESCO había desarrollado algunos programas para combatir la aridez en la región a comienzos de los 50 , el salto tanto cualitativo como cuantitativo en la discusión sobre este problema tendría lugar con la realización en 1977 de la United Nations Conference on Desertification que quiso abordar en Kenia la situación de los territorios sitos al sur del Sahara. Consecuencia directa de la popularización del término no sólo fue el traslado del eje de la discusión desde las estructuras políticas de la colonización al medio ambiente, sino la generación de una imprecisión categorial que afectó a la totalidad de las controversias. De hecho, en menos de una década el número de acepciones diferentes con que fue usado el concepto de desertificación pasó del centenar (Glantz y Orlovsky, 1983). La indefinición, valga 
la paradoja, de la definición, provocó secuelas perjudiciales a las miles de personas que vieron como sus diarios problemas crecían debido a un abordaje aparentemente neutral de la cuestión que, sin embargo, se anclaba en opciones e intereses políticos y económicos. La asunción de axiomas tautológicos — “el origen de la desertificación es el empobrecimiento de los suelos"-, que incluyen una confusión entre causas y efectos, propició la adicional dificultad de disociar procesos y estados al permitir que la desertificación se presentara ora como un proceso, ora como el estado resultante de un proceso o incluso como ambas cosas a la vez. En definitiva, la reflexión sobre qué fuera la desertificación y cómo se debía abordar, fue durante varias décadas presidida por el desconcierto. En cualquier caso, y más allá de las soluciones técnicas, el término, de uso común ya, ha sido definitivamente asociado a la producción de desiertos. La propia Real Academia Española de la Lengua, en su edición on line, define la palabra "desertificar" como "transformar en desierto amplias extensiones de tierras fértiles". Ahora bien, la identificación entre desierto y desertificación, aparentemente indiferente, ahonda en prejuicios derivados de la concepción "imperial" aludida en las páginas precedentes.

\section{La producción de desiertos}

Como promueve la mencionada concepción imperial, al habitante del territorio definido como desértico solamente le cabe, desde la perspectiva de quien pretende ocuparlo, integrarse en el nuevo modelo socioeconómico a través de la transformación productiva y la subsiguiente subordinación política. Sin embargo, ello no implica la desaparición de la frontera interior al otro lado de la que ha sido situado: el proceso forzoso de integración conlleva una desestructuración tanto de las relaciones sociales que hasta ese momento había mantenido con otros grupos humanos, como de sus relaciones con el medio. Es decir, en último término, ese proceso incluye siempre una asimilación formal que permite su expulsión hacia los márgenes de un sistema que, a la vez que le exige integración, se la impide y lo estigmatiza por ello. En todo caso, dos razones justifican que, una vez iniciado el proceso de asimilación, la vuelta atrás sea imposible por muchos movimientos de retradicionalización que pudiera haber. En primer lugar, porque se le impone una estructura que le atribuye la condición de "ciudadano", aunque sea subalterno, sujeto a obligaciones que impiden recuperar el tipo de relaciones que mantenía con el entorno y que hacen inútiles las etnoecologías particulares que permitían esas relaciones. Como consecuencia, se renuncia a las prácticas de manejo consuetudinarias y se sustituyen por otras de mercado que, al cabo, empobrecen lo suelos. En segunda instancia, la vuelta atrás resulta imposible porque una vez alteradas las condiciones ecosistémicas, no es posible regenerarlas para volver a la situación anterior. Así pues, la occidentalización, cabe decir "modernización productiva", se convierte en una ineludible exigencia porque, iniciada la integración, la vuelta a actividades peyorativamente calificadas como "de subsistencia", se torna inviable social, económica y ambientalmente. A mayores, no faltará quien de modo impune acuse a quienes intentan volver a usos "tradicionales" de ser los genuinos culpables de la extensión del desierto (Grainger, 1982). 
Inutilizadas las etnoecologías particulares para reducir los problemas que sobre el entorno provoca el desarrollo de una agricultura de mercado, se pretende que el único recurso que queda para solventar los problemas de degradación ambiental es el derivado de la utilización de los recursos técnicos generados en el mismo marco globalizador. Pero, esta intencional identificación genera igualmente consecuencias indirectas en distintos ámbitos del saber: por una parte, refuerza la creencia de que los problemas ambientales sólo podrán ser resueltos de manera técnica por científicos "naturales"; por otra, y en un plano diferente, contribuye a extender la convicción de que el mundo en su conjunto se está convirtiendo en un gigantesco desierto. Ahora bien, la identificación del problema como una cuestión "técnica" — cómo parar el avance del desierto - lo convierte en un proceso impersonal y desculpabilizador. Es más, si ab initio la desertización se hubiera definido como un proceso de empobrecimiento vinculado a los procesos descolonizadores, la atribución de causas humanas, políticas si se quiere, hubiera demandado la búsqueda de soluciones diferentes. Sin embargo, el término "desertificación" se ha anclado a un imaginario que torna las estructuras políticas en algo invisible y que pretende afirmar que si el desierto avanza no es porque el hombre en su pequeñez (o mezquindad) lo mueva, sino porque la naturaleza en su desmesura, lo desplaza de manera "ciega".

La precedente atribución permitirá a los círculos de poder de las antiguas metrópolis, sean cual sean las propuestas que los científicos - sociales o naturales - formulen, desvincular, por una parte, la discusión sobre la desertificación de los problemas de "descolonización" y, por otra, seguir influyendo en las antiguas colonias a través de ayudas humanitarias que, a la postre, aunque mitigan la miseria, impiden el desarrollo endógeno y requieren la occidentalización del país. Lo que de este aserto se deriva no es que las llamadas "actividades tradicionales" no puedan implicar prácticas vinculadas a una gestión ambiental negativa, sino que, en la mayor parte de las ocasiones, una determinada concepción occidentalizante del desierto como "lugar atributo" del que puede predicarse todo lo negativo, ha propuesto directamente la erradicación de cualquier actividad humana que no se ajuste a los parámetros de la agricultura euro-norteamericana. En este contexto, no falta quien quiera aprovechar la ocasión para extender ciertos principios ideológicos aseverando enfáticamente que la desertificación se ve acrecentada básicamente en las áreas en las que priman las tierras comunales. Como si el proceso (o estado) fuera ajeno a aquellos lugares en que la tierra está en manos privadas y no fuera, las más de las veces, consecuencia de la sobreexplotación de la misma por corporaciones multinacionales.

\section{Las tierras improductivas}

La identificación entre desiertos y tierras no productivas en términos acordes con las necesidades del mercado internacional no se limita al ámbito africano. Una década después de la reunión de Nairobi, el Programa de las Naciones Unidas para el Medio Ambiente, UNEP, desarrollaría el Proyecto Sands of change en el que la visión de un "desierto reptante" en continuo movimiento por todo el mundo fue reforzada con la idea de la "bomba de tiempo de la desertificación" (Thomas 
y Middleton, 1994): si no se hace nada en contra, llegará la gran explosión, más acertado sería implosión, y la productividad cero invadirá todo el mundo convirtiéndolo en un genuino y gigantesco desierto. Con ello, la desertificación dejó de ser un problema regional — del área que bordea el africano desierto del Sahara - para convertirse en un asunto mundial.

Así, a pesar de que las únicas tierras indesertificables serían las infecundas de los desiertos, se produjo un ilegítimo salto cuantitativo y cualitativo que se explica, en parte, por la efectividad de la falaz identificación entre desierto y desertificación. Esta aparente identidad resultó fortalecida porque, como señala el Plan de Acción para Combatir la Desertificación que desarrollara UNEP, la noción misma de desertificación "conlleva una connotación de desastre y no precisa de explicación. Prácticamente todo el mundo supo de manera intuitiva que la desertificación era mala, independientemente de a qué viniera referida" (Dregne, 1987: 8). En pocas palabras, con independencia de cuáles sean los elementos naturales que permiten caracterizar un territorio como desierto, la aludida unificación conceptual propició un error categorial resultante de trasladar miméticamente los atributos negativos con que ideológicamente había sido definido el desierto a la ausencia de producción agrícola derivada del agotamiento de los suelos fértiles.

Resuenan, así, los ecos de las invenciones del desierto chichimeca, del argentino o de las Grandes Llanuras estadounidenses que, como consecuencia de la identificación entre desierto e improductividad agraria, no pudieron ser contemplados ni como ecorregiones que incluyen complejos ecosistemas en los que flora y fauna sobreviven en condiciones de extrema aridez, ni con corredores que han comunicado históricamente lugares. Así pues, de la misma forma que esta concepción de los desiertos impidió conceptuarlos como "entre lugares" abiertos que permiten el encuentro entre pueblos o comunidades bióticas, la identificación entre desierto e improductividad agraria inserta al espacio devorado por el desierto en una lógica que, más allá de la binaria oposición lugar-no lugar, lo configura como la ausencia de lugar.

Asentada en ese marco categorial, la desertificación deja de aludir a la transformación y deterioro de ecosistemas particulares - aunque numerosos - para referirse a la generación de territorios vacíos que, aunque carente de todo, todo lo engullen hasta crear la nada. La recuperación de la idea del desierto como vasto, estéril y homogéneo territorio imaginario que, aunque deshabitado, se encuentra plagado de peligros - reptiles venenosos o fieras perdidas entre la inmensidad de las dunas que, cual bandidos, esperan emboscadas para atacar a los incautos que se adentran en dichos parajes - consigue, a su vez, que la desertificación también sea vista como un proceso homogéneo que sucede de igual forma en todas partes en que acontece. Se desconsidera así la posibilidad de que, afectando la desertización a ecosistemas particulares con condiciones específicas, las soluciones puedan ser también específicas para cada caso.

En cuanto antítesis del lugar civilizado - "en pocos sitios del mundo la vida es tan dura y al par tan desprovista de todo halago para vivirla", diría Neruda contemplando "La pampa salitrera"-, la identificación de desierto y desertificación 
permite concretar una de las amenazas que se ciernen sobre "nuestra" civilización. Desde este punto de vista, "los otros", los habitantes del desierto, se observan no como parte de la diversidad cultural, sino desde la perspectiva de una seguridad ambiental que, diseñada desde la óptica militar, está más interesada en detener a los migrantes expulsados de sus tierras por el avance de la desertización, que las causas que provocan ésta. Como si estos refugiados ambientales antecedieran con su avance al del propio desierto. ${ }^{1}$ En cualquier caso, si la identificación de un determinado territorio como "desierto" y de sus habitantes como "hostiles" tiene más que ver con necesidades políticas, sociales o económicas de quien así lo caracteriza que con las peculiares condiciones geofísicas o ambientales, habrá que colegir que los procesos o estados de desertificación que sobre él se predican, posiblemente también deban comprenderse desde esquemas teóricos semejantes.

Esta asimilación categorial permite comprender las bases neoliberales que han permitido la popularización de la desertización como uno de los grandes peligros para la humanidad. La definición de un espacio por el modo en que satisface expectativas e intereses agrícolas en lugar de por sus características ecosistémicas otorga un significado económico a un proceso que se quería "natural" y posee inmediatas consecuencias económicas y sociales: la reducción del potencial productivo - desertificación - hace que recursos económicos que iban a ser invertidos en dichos espacios sean desviados a otros lugares porque es imposible rentabilizarlos a corto plazo. Como consecuencia, se genera el abandono del lugar tanto por potenciales inversores como por las personas que lo habitaban, que se ven en la necesidad de emigrar debido al empobrecimiento del terreno y la marginación de las actividades productivas "tradicionales".

La equiparación de "vaciamiento" y desertificación acrecienta aún más la confusión derivada de la indeterminación de a qué llamamos tal. Una vez "vacío" el espacio, como si fuera un desierto, la desertificación pasa a ser vista como "el último paso de la degradación de las tierras, el punto en que las tierras se vuelven irreversiblemente estériles en términos humanos y con respecto a razonables limitaciones económicas" (Thomas y Middelton, 1994: 8). Con ello, se ha producido un nuevo salto conceptual porque, así considerada, la desertificación ya no es ni un proceso ni el estado final del mismo, sino una condición predicable de aquellos espacios que, al haberse visto "degradados", sea cual fuere la causa, han perdido su valor económico en términos de mercado. No extraña por ello que, en lugares cuya productividad económica ha mermado, aunque sea por razones muy diferentes de las plenamente ambientales, pueda haber sido enarbolada como bandera reivindicativa con el objeto de insertar dichos territorios en agendas políticas o económicas. Así, la imagen del desierto que repta y avanza hacia nosotros se convierte en un instrumento de control económico que, combinando la adhesión a los principios "verdes" con el miedo al

${ }^{1}$ Aunque los matices revelen concepciones diferentes del problema, no entro aquí a considerar qué concepto es más idóneo de los muchos utilizados por los diferentes teóricos de la cuestión (refugiado climático, eco-refugiado, desplazado ambiental, etc.). Me limito a constatar la relación existente entre una transformación ambiental (forzada) y una migración (igualmente forzada). 
Apocalipsis ambiental, propicia un incremento de la denominada ayuda cooperativa. Ahora bien, ésta, lejos de ser gestionada con criterios de desarrollo, en la medida en que los Estados han optado por hacer de la voluntad privada el eje de la acción solidaria, termina, a pesar de ser necesaria, aumentando la dependencia económica de los países empobrecidos respecto de agencias internacionales que no siempre carecen de ánimo de lucro. Se extiende además, porque, en la medida en que lo natural y lo cultural no son esferas independientes como quieren los positivistas más extremos, sino elementos de un continuum en el que se puede establecer una gradación, los conceptos que se querían asignar a lo natural terminan traspasándose al ámbito de lo cultural. Es decir, en la medida en que se considera la desertificación como un proceso inanimado e impersonal, las personas que viven en las áreas en que aquella avanza, serán contemplados, de acuerdo con el mismo aparato conceptual, como recipientes carentes de voluntad, "objeto de ayuda", pero no "sujeto activo" y protagonistas de sus propias decisiones. Como si el proceso de descolonización aún no hubiera concluido y los afectados por la desertificación fueran intelectualmente menores de edad.

\section{El avance de una desertización verde y sin arenas}

La continua superposición de las esferas económica, social y ambiental, permitiría suponer que la producción de desiertos no precisa de ecosistemas de características específicas: si las condiciones económicas lo demandan, un desierto puede ser creado en cualquier espacio. Como puede verse en las líneas siguientes, que son traídas aquí a título de ejemplo y en los que, por mor del espacio, no me extenderé de manera excesiva, a tal propósito puede contribuir la utilización confusa e indeterminada de conceptos como "sostenibilidad" u otros ligados históricamente a la defensa del medio ambiente.

Los incentivos económicos proporcionados por la dictadura brasileña durante las décadas de los 60 y 70 del pasado siglo XX permitieron a la industria maderera del país obtener un gran crecimiento económico merced a la generalización de plantaciones industriales de árboles. Aunque numerosos pueblos originarios fueron expulsados de sus tierras o tuvieron que adaptarse a la destrucción de su hábitat y economía, el éxito del programa hizo que se mantuviese e incluso potenciase durante los gobiernos democráticos. De hecho, desde que en 2003 el gobierno de Lula da Silva crease el Consejo Nacional de Bosques, el crecimiento del monocultivo industrial de árboles en Brasil ha sido casi exponencial. El éxito económico de este proyecto supuestamente ha sido seguido también por el ambiental: el Anuario 2011 del Programa de Naciones Unidas para el Medio Ambiente considera que estas plantaciones han tenido "efectos positivos" en el paisaje porque "han estabilizado el uso de las tierras y han revertido gradualmente la degradación de los bosques causada por el ganado" (Fleming, Kanowski et al., 2011: 52). Desde ese punto de vista, los beneficios habrían saltado desde los paisajes particulares a una más genérica "conservación de la biodiversidad, porque han creado condiciones favorables para la protección y regeneración de la Mata Atlántica" (ibídem). 
En esta misma línea, la organización ambientalista WWF (World Wide Fund for Nature), "como líder mundial en la conservación" ha diseñado una "nueva generación de plantaciones" que, sugiere, "bien manejadas", "pueden ser parte de la solución" a algunos de los problemas ambientales de nuestra época. Según WWF, este tipo de plantaciones puede diseñarse de modo que respeten "las áreas y recursos que son importantes para las comunidades." Pero, además, o tal vez sobretodo, "las plantaciones también pueden servir como una herramienta económica para financiar la restauración de los bosques, la conservación de la biodiversidad y los ecosistemas." (http://newgenerationplantations.com/) ${ }^{2}$. Reconoce, no obstante, el Fondo Mundial para la Naturaleza que, "mal gestionadas y mal ubicadas pueden causar un daño significativo a los hábitats naturales y componentes ecosistémicos como los ciclos del agua y de nutrientes, almacenamiento de carbono y la biodiversidad", añadiendo que "también pueden ser perjudiciales para las comunidades locales."

Ahora bien, si el WWF considera que estas plantaciones tendrán efectos positivos o negativos en función del tipo de gestión que se realice, en 2009, coincidiendo con el "Día Mundial de Lucha contra la Desertificación y la Sequía", la Red Latinoamericana contra los Monocultivos de Árboles (RECOMA) pidió a los gobiernos de dicha región que dejaran de impulsar los grandes monocultivos arbóreos debido a que "agravan los problemas de sequía y desertificación"”. La demanda, reiterada en los últimos quince años por numerosas organizaciones ambientalistas, considera que el impulso que ha dado a las plantaciones industriales de árboles el Foro de las Naciones Unidas sobre Bosques (UNFF), ${ }^{4}$ junto a las medidas adoptadas por los gobiernos del área en la misma dirección, son la principal causa de generación de "desiertos verdes". Tan sugerente concepto se ha popularizado desde que en 2004

${ }^{2}$ Además de en la web http://newgenerationplantations.com/, las características de este proyecto pueden verse en http://wwf.panda.org/what_we_do/footprint/forestry/sustainablepulppaper/plantations/. Según la primera de estas direcciones, en el proyecto de WWF participan organismos públicos como la Administración Forestal de China, la Comisión Forestal del Reino Unido, la Iniciativa Forestal de Suecia y el Gobierno del Estado Federado de Acre; y empresas privadas del sector forestal como CMPC, Forestal Mininco, Masisa, Fibria, Portucel, Sabah Forest Industries, Enso, Veracel y UPM-Kymmene.

${ }^{3}$ En 1995 la Asamblea General de Naciones Unidas instituyó el 17 de junio como Día Mundial de lucha contra la desertificación y la sequía. Desde ese año se conmemora anualmente, si bien parece que con escaso éxito. La "Red Latinoamericana contra los monocultivos de árboles" fue creada en 2003 por organizaciones ambientales de varios países sudamericanos durante el Foro Social Mundial para coordinar sus esfuerzos de oposición a la expansión de monocultivos forestales en el continente. Además de otras iniciativas, ha producido numerosos documentos que aparecen recogidos en su web: http://www.wrm.org.uy/plantaciones/RECOMA.html. El documento mencionado puede consultarse en http://www.wrm.org.uy/plantaciones/RECOMA/ Carta_Junio_2009.html. A comienzos de 2012, la red estaba conformada por organizaciones de Argentina, Bolivia, Brasil, Chile, Colombia, Costa Rica, Ecuador, El Salvador, Guatemala, Honduras, México, Nicaragua, Paraguay, Perú, Uruguay y Venezuela.

${ }^{4}$ El Foro de la Naciones Unidas sobre los Bosques, UNFF, fue creado en el año 2000 por el Consejo Económico y Social de Naciones Unidas con el objetivo de "fortalecer el compromiso político con la ordenación, la conservación y el desarrollo sostenible de todos los tipos de bosques." Desde ese año se reúne anualmente y presenta sus informes al Consejo Económico y Social. Sus documentos pueden consultarse en http://www.un.org/esa/forests/ 
un centenar de organizaciones ambientalistas brasileñas reunidas en Belo Horizonte crearan la "Red contra el Desierto Verde". En el documento fundador de dicha red, denominado "Manifiesto contra el desierto verde y a favor de la vida", los firmantes aseguraban que:

[E]l desastre socioambiental causado en los últimos 35 años por el monocultivo de eucalipto y pino, integrado a los complejos siderúrgicos y de celulosa, que afecta a diversos ecosistemas y poblaciones de nuestro territorio, [está] empobreciendo nuestra diversidad biológica, social y cultural y causando expropiación, desempleo, éxodo y hambre. (Rede, 2004)

La declaración prosigue indicando que este tipo de plantación "usa un pretexto ambiental para diseminar los monocultivos de árboles, generadores del desastre socioambiental [en el que] los permisos ambientales y los sellos verdes solamente han profundizado las desigualdades socioambientales. El modelo entero está comprometido con la lógica excluyente del latifundio de exportación, apropiándose de organismos públicos y legitimándose mediante certificaciones no participativas ni independientes" (Rede, 2004). Esto es, el avance de este tipo de plantaciones estaría ocultando una deforestación del continente ${ }^{5}$ y propiciando negativos efectos tanto en lo ambiental como en lo social y en lo económico. En síntesis, según RECOMA, los monocultivos de árboles

[...] están destruyendo bosques, praderas y humedales; están acabando con el agua; constituyen desiertos alimenticios para la fauna local y ocupan el espacio de la flora nativa; expulsan gente del medio rural, privándola de sus medios de supervivencia; resultan en un balance neto negativo en materia de trabajo a nivel local y los escasos y mal remunerados empleos que generan lindan en muchos casos con la semi-esclavitud. En resumen, tanto el ambiente como la sociedad locales resultan perjudicados por estos monocultivos.

(http://www.wrm.org.uy/plantaciones/RECOMA/Declaracion_UNFF.doc)

La mención a las disputas a propósito de los monocultivos arbóreos que aquí estoy realizando busca relacionar el modo en que en algunos debates contemporáneos acerca de la protección ambiental está inserta una continuidad entre la forma en que históricamente se "inventaron" los desiertos y la actual desertificación. Así se plantea explícitamente en la "Declaración de Quito. ¡Las plantas no son árboles!", efectuada por RECOMA en julio de 2004, en cuyo preámbulo se dice que la sustitución de un ecosistema por una plantación industrial equivale a la generación de un desierto:

$[\mathrm{N}] \mathrm{o}$ dejaremos que arrebaten nuestra esperanza quienes inundan hoy el Planeta con grandes monocultivos de árboles (eucalipto, pino, palma africana, teca y otros). Ellos nos arrebatan nuestras tierras y hacen de nuestro territorio un desierto donde ya los pájaros no cantan; siembran árboles para un consumo abusivo que termina

${ }^{5}$ Una visión de conjunto sobre los monocultivos de árboles en Iberoamérica puede verse en Overbeek et al. (2012). 
llenando de papel los basureros; ocupan nuestras tierras que ya no se destinan para resolver el hambre amenazante; desecan nuestros ríos y nuestros manantiales; engañan cuando prometen empleos que nunca llegan; expulsan a nuestras comunidades y desplazan la flora nativa dejando sin alimento a la fauna. Estas plantaciones de árboles, estos desiertos de verde monocromático, destruyen el arco iris de la diversidad biológica y homogeneízan y erosionan nuestras culturas.

(http://www.wrm.org.uy/actores/FSM/Quito.htm)

Por tal motivo, en un sentido muy diferente al defendido por WWF, RECOMA u otras organizaciones análogas, plantean que se está haciendo pasar por un bosque lo que es una factoría industrial concebida desde el punto de vista de la maximización de los beneficios económicos que excluye cualquier componente social o ambiental. Es decir, no se trata de una práctica bien o mal desarrollada, sino de un "modelo forestal" en sí mismo perverso que, so pretexto de "conservar los ecosistemas prístinos y respetar los derechos de las comunidades", subordina ecosistemas y personas a "los intereses mercantiles de empresas". Finalmente, sea negativa o adecuada la gestión de estas plantaciones, el resultado es la creación de "desiertos verdes y silenciosos" en los que no se puede habitar porque para que tengan éxito "estos cultivos son precedidos generalmente por la tala del ecosistema forestal nativo" (Ovando, 2008). En ese sentido, la crítica a los monocultivos de árboles enfatiza, que:

[E]l verdadero motor, causante de que todas estas actividades se realicen en forma depredadora e insustentable es el modelo de "desarrollo" vigente. Este implica la explotación irrestricta de la totalidad de los recursos del planeta, con el objetivo de alimentar un siempre creciente mercado consumidor [por lo que] lo único que tienen en común, los bosques nativos con las plantaciones, es la presencia de árboles. Un bosque es un sistema complejo, que se autoregenera y que incluye suelo, agua, microclima, energía y una amplia variedad de plantas y animales en mutua relación. Una plantación comercial, por el contrario, es un área cultivada, cuyas especies y estructura han sido drásticamente simplificadas para producir sólo unos pocos productos, ya sea madera, leña, resina, aceite o frutas. A diferencia de los bosques, en una plantación los árboles tienden a pertenecer a una reducida variedad de especies y la fauna no la habita, convirtiéndola en silenciosa. (Ovando, 2008)

Si la producción industrial de "naturaleza" muestra cómo se producen los desiertos verdes y silenciosos desde una visión economicista, en una dirección opuesta, el anclaje teórico neorromántico —cuando no religioso (Tomé, 2008) — que está en la base de algunas propuestas de protección ambiental, está propiciando una conservación de ciertos ecosistemas en condiciones taxidérmicas que terminan convirtiéndolos en idílicos desiertos multicolores. Esto ha ocurrido particularmente en aquellos casos en que ciertos territorios han sido "protegidos" siguiendo el modelo de "parques" o "reservas" del archiconocido Yellowstone.

Las declaraciones de Yosemite Valley en 1864 y de Yellowstone en 1872 como parques nacionales coincidieron en el tiempo con el auge de una ideología civilizatoria, coherente por lo demás, con el evolucionismo sociocultural que incluía la idea, entre otras, de que solamente el "civilizado hombre blanco" podía poseer valores 
morales. Desde esta perspectiva, considerar la opinión de los pueblos originarios no entraba en los planes de ningún gestor político para el que, cual si fueran habitantes del desierto, eran invisibles lastres en el avance del progreso. Por lo mismo, "los maravillosos paisajes y los extensos territorios vírgenes eran, para la legalidad de los invasores, terra nullius, y esperaban sólo que el genio occidental contemporáneo llegase para reconocer su valor estético y científico para la posteridad" (Mallarach, 1996: 28). En suma, los habitantes de lo que luego fueron los parques nacionales se encontraron ante el "avance civilizador" en la misma tesitura y frente a los mismos argumentos contra los que se tuvieron que enfrentar los del desierto chichimeca cuando arribaron los conquistadores: la creación de una "reserva natural" exigía, como primera medida, desalojar a esos incómodos habitantes, por cualquier tipo de procedimiento, $\mathrm{y}$

[...] prohibirles que continuaran sus aprovechamientos seculares: caza o pesca de subsistencia, recolección de frutos, raíces; cortezas, quemas controladas, etc., puesto que para los conservacionistas de mentalidad urbana todo ello resultaba incompatible con su futura promoción como tesoros de patrimonio natural. (Mallarach, 1996: 26)

Dicho de otro modo, para convertir un espacio en "museo natural" era necesario vaciarlo, declararlo desierto, aunque fuera a costa de profundizar en la paradoja de afirmar que aquellos humanos que eran considerados apegados a "lo natural" eran incapaces de gestionar la naturaleza pues esta es capacidad no natural sino "civilizada". Fue así, como, en el último tercio del siglo XIX, los habitantes de las tierras salvajes que se quisieron proteger (de los salvajes), se convirtieron en lo que hoy llamamos refugiados ambientales: por razones "ecológicas" fueron expulsados de unos territorios a los que estaban "adaptados", desplazándolos a cambio a otros que no conocían - las reservas - en las que su único destino posible era la miseria. Esto significa que la declaración de un espacio como Yellowstone como Parque Nacional supuso, de facto, la creación de dos tipos de reservas: "un[a] para los pobladores indígenas [las Native American Reservations] y otr[a] para la naturaleza virgen" (Mallarach, 1996: 27).

Esta patrimonialización de la naturaleza, vía musealización de la misma, resultaba coherente con una concepción romántica del paisaje que se asienta en la idea de que cualquier espacio puede ser edénico si no está habitado por humanos. Y así, de la misma forma en que Adán y Eva fueron expulsados de un cerrado paraíso por alterarlo, los indígenas fueron desalojados de un terreno que quienes no lo habitaban querían convertir en ese mítico Edén. Pero, más allá de la convicción de que naturaleza y sociedad son términos antitéticos, este desahucio olvidó que casi todos los territorios "inalterados" que conocemos, tal vez la excepción sea la Antártida, han llegado hasta nosotros como los conocemos como consecuencia de la acción de sus moradores. Como pone de manifiesto lo acontecido en Yellowstone, la expulsión de los "habitantes tradicionales" de un territorio puede generar más problemas ambientales a largo plazo que beneficios, por mucho que estos sean evidentes en el corto. En el caso del mencionado parque norteamericano, la desaparición del "complejo 
manejo de los ecosistemas que venían practicando los pueblos indígenas desde tiempos inmemoriales" (Mallarach, 1996: 30), se tradujo en un gran desequilibrio natural, acrecentado por la construcción de carreteras que permitieran la llegada de los turistas y la necesidad de aniquilar gran parte de los grandes predadores (lobos, pumas, etc.) para evitar ocasionales daños a los visitantes ${ }^{6}$.

La conversión de un determinado espacio en un lugar pensado para ser visitado, por tanto como espacio de ocio y consumo, y no para ser vivido, supone la inserción del mismo en circuitos comerciales. O si se quiere más claro, comporta una nítida mercantilización del territorio que, en cuanto mera mercancía, deja de ser, paradójicamente, naturaleza. Y, sin embargo, ciento treinta años después de esos primeros parques, parte de las bases teóricas que sirvieron para protegerlos siguen estando presentes en las discusiones que se suscitan cotidianamente en cada intento de promover algún espacio protegido (Beltrán et al., 2008). No extraña por tanto, que sea frecuente que los habitantes de las zonas a proteger se rebelen contra estos intentos administrativos, incluso violentamente, alegando que se quiere convertir el lugar referido en un "desierto" como consecuencia de una voluntad política. En este sentido, como han puesto de manifiesto numerosos autores, el quid de la cuestión es la contradicción entre presupuestos antiecológicos - la regulación de lo natural mediante su mercantilización (Petras y Veltmeyer, 2002) - y prácticas supuestamente ecológicas (la protección del territorio aludido) que, sin embargo, generan un "impacto" sobre las zonas a proteger y, especialmente, sobre sus áreas limítrofes que, al profundizar en su desertificación, se torna "insostenible".

Ahora bien, este contrasentido es posible debido a la predominancia de una concepción insular de lo natural según la cual algunos espacios son "más naturales" que otros. Sin embargo, la determinación de qué es más natural obedece exclusivamente a una construcción sociocultural de lo natural que se concreta en voluntades políticamente enfrentadas que ponen de manifiesto una división territorial del mundo. Ésta determina qué espacios han de dedicarse a qué tipo de producciones. Así, uno de los efectos de la globalización, más allá de los beneficios inherentes a cualquier tipo de protección ambiental, es el establecimiento de ciertas áreas "improductivas", tan nítidamente delimitadas como si de islas se tratara, para una ocupación transitoria que se ha de regir por los parámetros del mercado turístico. Por lo mismo,

${ }^{6}$ De hecho, todavía hoy día se discute si se debe limitar la población de alces y otros herbívoros que están llevando al límite la "capacidad de carga" del parque mismo como consecuencia de su sobreabundancia. Aunque la discusión sobre el modo en que debe regularse Yellowstone es recurrente desde la década de 1920 (Huff y Varley, 1999), la expulsión en su día de los indígenas generó un "desierto" que tuvo efectos perniciosos tanto para ellos como para los espacios "vírgenes" pues la aparente regulación natural, que algunos creían que había permitido su conservación, se mostró insuficiente sin su presencia (Chase, 1986). Por su parte, Sara Rinfret ha mostrado cómo la actual reintroducción de osos, lobos, y otros animales está subordinada a una economía turística en la que los visitantes demandan el contacto con una naturaleza "salvaje" y simultáneamente dócil. Resulta "irónico en el mejor de los casos, e inauténtico en el peor, que los gestores de las especies, estén utilizando tecnología avanzada para aplicar una forma de disciplina foucaultiana, la creación de un "salvaje" que no es natural, sino construido por medios humanos" (Rinfret, 2009: 577). 
en cuanto que "desiertos improductivos", en el sentido expresado más arriba, sus habitantes, si los hubiera, se convierten en invisibles —en cuanto a la voluntad política-, que deben elegir entre marcharse o "integrarse" en el sistema de mercado proporcionando servicios a los turistas o exhibiéndose para que estos, contemplando su "primitividad" refuercen su autoconciencia de "civilizados". Sea como fuere, una vez definidos globalmente, cabe decir mercantilmente, los espacios de ocio no pueden "alterarse" porque es su inmutabilidad (su desértico silencio), lo que garantiza su productividad turística en el marco mundial.

Frente a este tipo específico de regulación ambiental, una concepción que, más allá de las nociones insulares del territorio, defiende su protección integral, aunque conceda niveles operativos de gradación, demanda una adecuada articulación de los beneficios económicos, sociales y ambientales. Si cualquiera de estos ámbitos crece a expensas de alguno de los otros dos, el resultado puede ser aceptable o incluso, desde ciertos parámetros, equilibrado, pero no sostenible. Es decir, no puede ser considerado como sostenible, por mucho que se reclame desde ciertas posiciones políticas, aquello que provoca efectos ambientales positivos a costa de incrementar las desigualdades sociales (o viceversa), por mucho que se defienda como mecanismo para "detener la desertificación del mundo" o garantizar la protección ambiental de ciertas áreas. Es decir, la ralentización o suspensión del avance de la "desertización del mundo", al igual que la adopción de medidas protectoras de determinados ecosistemas, debe hacer que los beneficios económicos se subordinen al objetivo de disminuir los desequilibrios ecosociales, incluyendo a los habitantes de los territorios afectados. Invisibilizarlos considerándolos "otros" hostiles que deben abandonar el territorio en aras a unos supuestos beneficios globales, es avanzar en la degradación de esos mismos espacios, convirtiéndolos en efectivos "desiertos", por mucha vegetación que puedan tener, por el mismo procedimiento con que históricamente se han creado estos. Claro que para ello debe abandonarse una lógica asentada en la mercantilización de lo natural que deje de identificar lo "improductivo" desde las leyes de mercado con el desierto.

\section{Referencias bibliográficas}

ALDHUY, Julien y PUYO, Jean-Yves

2007 "Savoirs géographiques et construction des hauts lieux paysagers français: l'exemple des Landes de Gascogne (XIX-XX siècles)". Ería, 73-74: 237-251.

AUBREVILLE, André

1949 Climats, forêts et désertification de l'Afrique tropicale. Paris: Soc d'éditions géographiques maritimes et coloniales.

BALLINAS, Juan

1951 El desierto de los lacandones. Memorias. 1876-1877. Tuxtla Gutiérrez, Chis.: Publicaciones del Ateneo de Chiapas.

BELTRÁN, Oriol; PASCUAL, José J.; VACCARO, Ismael (Coords.)

2008 Patrimonialización de la naturaleza. El marco social de las políticas ambientales. San Sebastián: FAAEE-ANKULEGI-UPV. 
BLOCH, Maurice

1989 "From cognition to ideology" en M. Bloch. Ritual, History and Power. Selected Papers in Anthropology. Londres y Atlantic Higlands, N.J. (USA): The Athlone Press: 106-136.

BLÜHDORN, Ingolfur

2000 "Construction and Deconstruction: Ecological Politics after the End of Nature" en A. Warhusrt (ed.). Towards a Collaborative Environment Research Agenda: Challenges for Business and Society. Basingstoke: Macmillan: 237-261.

CARRILLO, Alberto

2000 El debate sobre la guerra chichimeca. 1531-1585. Zamora, Mich.: El Colegio de Michoacán-El Colegio de San Luis.

CASTREE, Noel

2008 "Neoliberalising nature: the logics of deregulation and reregulation". Environment and Plannig. 40(1): 131-152.

CORTÉS, Hernán

1986 [1526] “Quinta Carta-Relación al Emperador”. En Cartas de Relación. Barcelona: Océano.

CHASE, Alston

1986 Playing God in Yellowstone. The Destruction of America's First National Park. New York: The Atlantic Monthly Press.

DESCOLA, Philippe

2001 [1986] “Construyendo naturalezas: Ecologías simbólica y práctica social”, en Descolá, y G. Palsson (Coords.) Naturaleza y sociedad. Perspectivas antropológicas. México: Siglo XXI: 101-123.

DREGNE, Harold E.

1987 “Reflections of the PACD”. Desertification Control Bulletin, 15: 8-11.

ELLEN, Roy F.

2001 [1986] "La geometría cognitiva de la naturaleza. Un enfoque contextual", en P. Descolá, y G. Palsson (Coords.) Naturaleza y sociedad. Perspectivas antropológicas. México: Siglo XXI: 124-146.

ESCOBAR, Arturo

1999 “After Nature. Steps to an Antiessentialist Political Ecology". Current Anthropology 40(1): 1-30.

2000 "El lugar de la naturaleza y la naturaleza del lugar: ¿globalización o postdesarrollo?", en E. Lander (Comp.) La colonialidad del saber: eurocentrismo y ciencias sociales. Perspectivas latinoamericanas: 68-98 Buenos Aires: CLACSO. Disponible también en http://www.unc.edu/ aescobar/text/esp/lugardenaturaleza.pdf

EZCURRA, Exequiel (Ed.)

2006 Global Deserts Outlook. Nairobi: UNEP. 
FLEMING, Richard; ANOWSKI, Peter et al.

2011 "Nuevas perspectivas sobre la diversidad forestal". Anuario PNUMA. Temas emergentes en nuestro medio ambiente global. Nairobi (Kenia): Programa de las Naciones Unidas para el Medio Ambiente. 47-60.

GIMÉNEZ, Gilberto; HÉAU, Catherine

2008 "El desierto como territorio, paisaje y referente de identidad", en A. Fábregas et al. (eds.) Continuidad y Fragmentación de la Gran Chichimeca. Guadalajara, Jal.: SPECH: 63-93.

GLANTZ, Michael H.; ORLOVSKY, Nicolai.

1983 "Desertification: a review of the concept". Desertification Control Bulletin, 9:15-22.

GRADIE, Charlotte M.

1944 "Discovering the Chichimecas". The Americas, 51: 67-88.

GRAINGER, Alan

1982 Desertification: how people make deserts, how people can stop and why they don't. Londres: Earthscan.

HARVEY, David

1993 "The nature of environment: the dialectics of social and environmental change". The Socialist Register, vol. 29:1-51.

HUFF, Dan E.; VARLEY, John D.

1999 "Natural Regulation in Yellowstone National Park's Northern Range". Ecological Applications 9-1: 17-29.

INGOLD, Tim

1986 The appropriation of nature: Essays on human ecology and social relations. Manchester: Manchester University Press.

LEFEBVRE, Henri

1974 La production de l'espace, París: Anthropos.

LOIS, Carla Mariana

1999 "La invención del desierto chaqueño. Una aproximación a las formas de apropiación simbólica de los territorios del Chaco en los tiempos de formación y consolidación del Estado nacional Argentino". Scripta Nova. Revista Electrónica de Geografía y Ciencias Sociales, 38.[http://www.ub.es/geocrit/sn-38.htm]

MCKIBBEN, William

1990 El fin de la naturaleza. Barcelona: Ediciones B.

MALLARACH, Josep M.

1996 "Parques nacionales versus reservas indígenas en los Estados Unidos de América: un modelo en cuestión". Ecología Política 10: 25-35.

\section{MARQUÉS DE ALTAMIRA}

1944 [1748] Dictamen del auditor de guerra Marqués de Altamira sobre Pacificación de los chichimecas de la Sierra Gorda. México: Vargas Rea. 
MILTON, Kay

1997 "Ecologías: antropología, cultura y entorno". The International Social Science Journal, 154. www.unesco.org/issj/rics154/miltonspa.html

NAVARRO, Pedro

2001 "El salvaje y su tratamiento en el discurso político argentino sobre la frontera sur, 1835-1879”. Revista de Indias, vol. LXI, n 222: 345-376.

2002 "El desierto y la cuestión del territorio en el discurso político argentino sobre la frontera Sur". Revista Complutense de Historia de América, 28: 139-168.

O'CONNOR, James

1992 "Las dos contradicciones del capitalismo", en J. Martínez Alier (Coord.) Ecología Politica. Cuadernos de debate internacional 3: 111-112.

OVANDO, Norberto

2008 "Desiertos verdes y silenciosos", en Biodiversidad en América Latina y El Caribe. Disponible en http://www.biodiversidadla.org/content/view/full/43991

OVERBEEK, Winfridus ; KRÖGER, Markus; GERBER, Julien-François

2012 "An overview of industrial tree plantations in the global south conflicts trends and resistance struggles". Environmental Justice Organisations, Liabilities and Trade (EJOLT) Report No. 3. (Disponible en www.ejolt.org/2012/06/an-overview-ofindustrial-tree-plantations-in-the-global-south-conflicts-trends-and-resistancestruggles/)

PETRAS, James; VELTMEYER, Henry

2002 El imperialismo en el siglo XXI. La globalización desenmascarada. Madrid: Popular.

PONCE, Fray Alonso

1873 [1587] "Relación breve y verdadera de algunas cosas de las muchas que [le] sucedieron". En Documentos Inéditos para la Historia de España. Tomo LVIII. Madrid: Imp. Miguel Ginesta.

POWELL, Phillip W.

1971. War and Peace on the North Mexican Frontier: A Documentary Record. Volume I. "Crescendo of the Chichimeca War" (1551-1585). Madrid: Ed. José Porrúa Turanzas.

REDE Alerta contra o Deserto Verde-WRM-Movimiento Mundial por los Bosques Tropicales.

2004 "Brasil. Manifiesto contra el desierto verde y a favor de la vida". http://www.wrm. org.uy/paises/Brasil/manifiesto.html).

RINFRET, Sara

2009 "Controlling Animals: Power, Foucault and Species Management". Society and Natural Resources, 22: 571-578.

ROSALDO, Renato

1978 "The Rhetoric of Control: Ilongots Viewed as Natural Bandits and Wild Indians", en B. Babcock (ed.). The Reversible World: Symbolic Inversion in Art and Society. Ithaca, N.Y.: Cornell University Press, 240- 257. 
SAHAGÚN, Fray Bernardino

1995 [1547-1558] Historia general de las cosas de la Nueva España. Madrid: Alianza Universidad.

SÁNCHEZ ALBORNOZ, Claudio

1966 Despoblación y repoblación del Valle Duero. Buenos Aires: Instituto de Historia de España.

SANTA MARÍA, Fray Guillermo

2003 [1575-1580] Guerra de los Chichimecas. Zamora, Mich.: El Colegio de MichoacánUniversidad de Guadalajara-El Colegio de San Luis. $2^{\mathrm{a}}$.

SANTAMARINA, Beatriz

2006 Ecología y poder. El discurso medioambiental como mercancía. Madrid: Libros de la Catarata.

2009 "De parques y naturalezas. Enunciados, cimientos y dispositivos". Revista de Dialectología y Tradiciones Populares RDTP, vol. LXIV-1: 277-296.

SCOONES, Ian

1999. "New Ecology and the Social Sciences: What Prospects for a Fruitful Engagement?", Annual Review Anthropology. 28: 479-507.

STRATHERN, Marilyn

1980. "No nature, no culture. The Haguen case", en MacCormack, Carol y Marilyn Strathern (Eds.). Nature, culture, gender. New York: Cambridge University Press: 174-222

THOMAS, David S.G.; MIDDLETON, Niholas J.

1994. Desertification. Exploding the Myth. Chichester (R.U.): John Wiley \& Sons.

TOMÉ, Pedro

2003 "La cuestión de autor a propósito de "Guerra de los Chichimecas". En Fray G. de Santa María Guerra de los Chichimecas. Zamora, Mich.: El Colegio de MichoacánUniversidad de Guadalajara-El Colegio de San Luis. 2a: 11-27.

2008 "La construcción social de la región cultural: territorios inteligentes, biorregiones y regiones culturales. Una aproximación ecológico cultural”, en A. Fábregas et al., Regiones y esencias. Estudios sobre La Gran Chichimeca. México: SPECH, 117-141.

2010 "Redescubriendo la Gran Chichimeca: Revalorización regional y antropología social en la recuperación de una pluralidad étnica mexicana". Revista de Dialectología y Tradiciones Populares, 65-1: 155-184. (doi: 10.3989/rdtp.2010.008).

2012 a "El desierto como categoría colonial”. En A. Fábregas, M.A. Nájera y C. González (Coords.). Transversalidad y paisajes culturales. Estudios sobre la Gran Chichimeca. Guadalajara, Jal.. SEPECH: 47-66.

2012 b "La invención del desierto (y los salvajes chichimecas)". En A. Fábregas, M.A. Nájera y C.M. Valdés (Coords.) Dinámica y transformación de la región chichimeca. Guadalajara, Jal.. SEPECH: 49-67.

TURNER, Frederick

1961 Frontier and Section, en R.A. Billington (comp.). Frontier and Section. Selected Essays of Frederick Jackson Turner. Englewood Cliffs, NJ: Prentice-Hall. 